\title{
Verklarende prediking. Basisteoretiese elemente uit Hebreërs
}

\author{
C.J.H. Venter \\ Vakgroep Praktiese Teologie \\ Skool vir Kerkwetenskappe \\ Potchefstroomse Universiteit vir $\mathrm{CHO}$ \\ POTCHEFSTROOM \\ E-pos: kwscjhv@puknet.puk.ac.za
}

\begin{abstract}
Expository preaching. Basis-theoretical elements from Hebrews

This article specifically focuses on basis-theoretical elements in the Letter to the Hebrews - a New Testament book that can actually be regarded as a sermon. In the introduction the point of departure, that is the focus on bais-theoretical elements, is justified. Furthermore, attention is paid to specific elements of preaching implied in this "sermon" in the Letter to the Hebrews: elements applicable to the practice of expository preaching, the structure in an expository sermon, that is the introduction, the body, and the conclusion. The purpose of the sermon is also touched upon. Issues like the spirituality of the preacher, his ministry of equipping by means of expository preaching, and his relationship to the congregation are also investigated, followed by final conclusions.
\end{abstract}

\section{Inleiding}

Onder die term verklarende prediking word vir die doeleindes van hierdie artikel verstaan die bediening van 'n kleiner of groter gedagte-eenheid uit die Skrif (dit wil sê 'n preekteks) wat deur die prediker self deurleef is en sodoende op die gemeente in hulle konkrete situasie gerig word (Venter, 2001:4). Dit is opvallend dat in resente literatuur op die gebied van die Homiletiek daar ' $n$ sterk gerigtheid is op navorsing juis oor verklarende prediking. Verskeie fasette word betrek in die ondersoek, byvoorbeeld die geskiedenis van verklarende prediking (Stitzinger, 1992:5-33), elemente van verklarende prediking (Chapell, 1995:4-14), die gesag in verklarende prediking (Allen, 2000:489-516), die nadere definiëring van verklarende prediking (Bugg, 1993:415) en die kwessie van toepassing in so 'n preek (Robinson, 1997:21-27). Ook die plek van die hoorder word betrek in die ondersoek (Willhite, 1992:355-369). 
Binne die studieveld soos hierbo genoem, word die Bybelse elemente vir verklarende prediking ook ondersoek. Deuel (1991:125-138) ondersoek elemente in die Ou-Testament wat verband hou met verklarende prediking. Hierin fokus hy veral op Deuteronomium 31 en 32 en op die "prediking" van Esra in die boek Esra en in Nehemia (vgl. ook Dennisson, 1996:4).

Lawson (2001:198-217) ondersoek Handelinge 2:42-47 met die oog op verklarende prediking en Chapell (1995:4-14) wy aandag aan 1 Timoteus 4 om verklarende prediking nader te fundeer. In hierdie ondersoeke is dit vreemd dat min nadere ondersoek oor basisteoretiese elemente juis in Hebreërs nog gedoen is. Ondersoek in Hebreërs is al - by wyse van voorbeelde - gedoen oor dimensies van gemeente-opbou (Venter, 1986), oor die teologie van Hebreërs (Lindars, 1991), oor die agtergrond van dié boek (Hurst, 1990) en nog meer onlangs oor die motief van vreemdelingskap en vaderland in Hebreërs (Opperman, 1995). Outeurs stel wel dat ons moontlik in Hebreërs te doen het met 'n homilie waarby 'n briefslot bygevoeg is (Grosheide, 1955:42; Opperman, 1995:26). Coetzee (1986:25-27) lei uit 'n ontleding van die breë struktuur van Hebreërs af dat ons wel hier met 'n verklarende preek te doen het - 'n preek ter bemoediging (Hebreërs 13:22-25).

As dit dan so is dat Hebreërs redelik wyd onder navorsers as 'n preek beskou word en as dit so is dat vanuit die Praktiese Teologie, in besonder vanuit die Homiletiek, nog min navorsing gewy is aan Hebreërs as preek, dan dui hierdie gebrek aan navorsing op 'n leemte in bestaande literatuur op die gebied van die Homiletiek. Die doel met hierdie artikel is gevolglik om deur ondersoek moontlike homiletiese elemente vir verklarende prediking in Hebreërs nader te ondersoek, te omlyn en te presiseer met die oog op die praktyk van verklarende prediking. Die metode van ondersoek is analise en interpretasie en die navorsingshipotese is dat ' $n$ nadere ondersoek van homiletiese elemente in Hebreërs as riglyne sou kan dien vir die samestelling van verklarende preke.

\section{Die element van preekstrukturering}

Homilete is bykans eenstemmig dat struktuur in 'n preek veral drie funksies het:

- dat dit bydra tot "the power of a sermon" (Long, 1989:92);

- dat struktuur dien tot kohesie van die materiaal wat aan die orde kom en 
- dat die struktuur ook lei tot logiese progressie: die preek moet iewers heen gaan, op 'n bepaalde doel afstuur (vgl. Bae, 1991:18; Vines, 1985:104). As gelet word op die wyer- en nadere gedagtestruktuur van die Hebreërpreek, dan bevestig die struktuur van die brief genoemde drie funksies van struktuur in 'n preek.

Hebreërs as preek is fyn en vernuftig gestruktureer en het 'n verhewe taalgebruik (Kistemaker, 1984:6). Die strukturering van enkele outeurs word hier weergegee ter wille van 'n oorsig oor die preek.

\subsection{Guthrie (1994) se strukturering}

Guthrie (1994:117) bied die volgende struktuur van Hebreërs:

Inleiding (1:1-4): God het met ons gepraat deur sy Seun

- Die posisie van die Seun in verhouding tot die engele (1:5-14)

- Die posisie van die Seun, ons Hoëpriester, met betrekking tot die aardse offersisteem, met as inleiding: ons het 'n sondelose Hoëpriester wat die hemel ingegaan het (4:14-10:18).

- Slot: Ons het 'n groot Hoëpriester wat ons die hemel inneem $(10: 19-25)$.

\subsection{Hewitt (1975) se indeling}

Hewit (1975:47-48) bied 'n enigsins wyer indeling:

- Inleiding (1:1-4)

- Die Seun verhewe bo die engele (1:5-2:18)

- Die Seun verhewe bo Moses (3:1-4:13)

- Die genadige en groot Hoëpriester (4:14-5:10)

- Geestelike vooruitgang (5:11-6:20)

- Die priesterskap van Christus, sy bediening en offer (7:1-10:18)

- Aanmoediging en vermaning (10:19-12:29)

- Finale, praktiese bemoediging (13:1-25)

\subsection{Coetzee (1986): gedagtestruktuur van en motiewe in Hebreërs}

Coetzee (1986:8-9) bied 'n nog breër gedagtestruktuur van Hebreërs, waarby in hierdie artikel aangesluit gaan word (numering en formatering ietwat gewysig - CJHV). 


\subsubsection{Gedagtestruktuur van Hebreërs}

Analise van die gedagtestruktuur van die Hebreërpreek

Tema: Ons het reeds in Christus die heerliker dinge beërf - volhard dan nou soos dit erfgename van die beloofde, volmaakte erfdeel betaam.

\section{1:1-4 Inleidende preekfondament}

Jesus deur Wie alles gemaak is, is Erfgenaam-Koning van alle dinge.

1:5-10A. Wat ons in Christus beërf het - as waarborg vir en dryfveer tot dit wat ons nóg moet beërf - explicatio.

1:5-2:18: Jesus - deur lyde en vernedering verhef tot 'n Naam en 'n heerskappy heerliker en groter as dié van die Engele - Hy lei ons na volle heerlikheid.

\subsubsection{Motiewe in Hebreërs}

\section{Skeppingsmotief}

- 1:(4), 5-14 : 'n Groter Naam: Seun, God, Here.

- 2:1-4 : Paraklese: "nie miskien wegdrywe ..."

- 2:5-8a : 'n Heerskappy waaraan alle dinge, ook die toekomstige wêreld, onderwerp is.

- 2:8b-18 : $\quad$ Langs die weg van vernedering, en lyde ter wille van ons tot sy heerlikheid, en tot ons heerlikheid (vgl. vs. 10).

\section{Uittog-intogmotiewe}

- 3:1-16: Jesus - Seun oor God se huis - heerliker as Moses - Hy maak ons deelgenote, medekinders in die huis van God.

Paraklese: 3:6: "Vrymoedigheid en hoop tot die einde toe vashou".

3:12-15: "nie van die lewende God afvallig word nie ... as ons ... tot die einde toe vashou".

- 3:17 - 4:13: Jesus - Gewer van die ware sabbatsrus vir die volk van God - groter as Josua.

Paraklese: 4:1, 11: "Beywer ... om in te gaan tot in die rus ... en nie miskien agterbly ... deur in ongehoorsaamheid te val nie".

- 4:14 - 10:18: Jesus - die Volmaakte Hoëpriester - open vir ons eens en vir altyd die weg na God se allerheiligste troon. 
Paraklese ter inleiding: 4:14-16: “... Laat ons die belydenis vashou ... deur met vrymoedigheid na die troon van genade te gaan”.

\section{Kultiese motiewe}

- 5:1-7:28: Jesus - groter as Aäron - synde priester volgens die orde van Melgisedek.

Grotere paraklese: 5:11-6:20: Die noodsaak van groei tot volwassenes in die geloof.

- 8:1-3: Jesus - Middelaar van die beter verbond - beter as die Ou Verbond.

- 9:1-10:18: Jesus - Hoëpriester van die beter, volmaakte, eenmalige offer - in die ware tabernakel.

- 10:19-13:19 : Die groot paraklese - applicatio.

- 10:19-2:29 : Volhard dan, sodat julle erfgename mag wees van die beloofde, volmaakte erfdeel.

- 13:1-19 : Opwekking/Bemoediging tot 'n praktiese Christelike lewenswandel as 'n lofoffer aan God (vgl. vers 15).

- 13:20-21 : Preekslot: Dit was 'n $\lambda^{`} \gamma_{\mathrm{O}} \mathrm{H}_{\tau} \not \mathrm{H}_{\pi} \alpha \rho \alpha \kappa \lambda \mathrm{Z} \sigma, \mathrm{TH}$

- 13:22-25 : Briefslot.

Vir ons doeleindes - om basisteoretiese elemente vir verklarende prediking te ondersoek - is dit egter nie net van belang om te let op die oorsigtelike of op die gedagtestruktuur van Hebreërs nie, maar in besonder om te let op die plasing binne dié struktuur van bepaalde preekelemente, naamlik dié van eksplikasie en applikasie. Uit die gedagtestruktuurontleding van Coetzee hierbo is dit reeds duidelik dat verklaring en toepassing in die Hebreërpreek mekaar telkens afwissel (en so die standpunt versterk dat ons hier met 'n preek te doen het).

Van hierdie afwisseling en plasing van verklaring en toepassing binne die Hebreërpreek, het Guthrie (1994:127-134) 'n besondere studie gemaak. Hy toon binne die struktuur van Hebreërs sekere beweging aan in verklaring en toepassing wat soos volg weergegee word: 


\subsection{Verklaring en toepassing in Hebreërs volgens Guthrie}

\begin{tabular}{|c|c|}
\hline Verklaring & Toepassing \\
\hline $\begin{array}{l}\text { Inleiding (Hebreërs 1:1-4) } \\
\text { God het met ons gepraat in die } \\
\text { Seun. }\end{array}$ & $\begin{array}{l}\text { Toepassing (Hebreërs } 2: 1-4 \text { ) } \\
\text { Gryp vas aan die Woord wat } \\
\text { gehoor is. } \\
\text { Nie wegdrywe nie. }\end{array}$ \\
\hline $\begin{array}{l}\text { Hebreërs 3:1-6 } \\
\text { Jesus die Apostel en Hoëpriester } \\
\text { van die geloof. }\end{array}$ & $\begin{array}{l}\text { Toepassing (Hebreërs } 3: 7-19 \text { ) } \\
\text { Hulle wat ongehoorsaam is aan die } \\
\text { Woord sterf in die woestyn. }\end{array}$ \\
\hline $\begin{array}{l}\text { Hebreërs } 4: 3-11 \\
\text { Die belofte van rus vir hulle wat } \\
\text { gehoorsaam was. }\end{array}$ & $\begin{array}{l}\text { Toepassing (Hebreërs } 4: 12-13 \text { en } \\
\text { 14) } \\
\text { Bly by die skerp, lewende Woord. } \\
\text { Hou vas aan die geloof wat ons } \\
\text { bely. }\end{array}$ \\
\hline $\begin{array}{l}\text { Hebreërs } 5: 11-6: 3 \\
\text { Die situasie in die gelowige ge- } \\
\text { meenskap. } \\
\text { (Traag om te hoor). }\end{array}$ & $\begin{array}{l}\text { Toepassing } \\
\text { Die gevaar om afvallig te word van } \\
\text { die Christelike geloof. }\end{array}$ \\
\hline $\begin{array}{l}\text { Hebreërs 6:4-8 } \\
\text { Hebreërs 6:9-12 } \\
\text { Die prediker se vertroue in die } \\
\text { hoorders. }\end{array}$ & $\begin{array}{l}\text { Toepassing } \\
\text { Hebreërs 10:26-32 } \\
\text { Die gevaar om God se waarheid en } \\
\text { sy Seun te verwerp. }\end{array}$ \\
\hline $\begin{array}{l}\text { Hebreërs 11:1-40 } \\
\text { Die positiewe voorbeeld van die } \\
\text { geloofsgetuies. }\end{array}$ & $\begin{array}{l}\text { Toepassing } \\
\text { Hebreërs 12:1-2 en 3-17 } \\
\text { Volhard in die geloofswedloop. } \\
\text { Verduur God se tugtiging. }\end{array}$ \\
\hline $\begin{array}{l}\text { Hebreërs 12:18-14 } \\
\text { Die seëninge van die nuwe } \\
\text { verbond. }\end{array}$ & $\begin{array}{l}\text { Toepassing } \\
\text { Hebreërs 12:25-29 } \\
\text { Moet nie God se Woord verwerp } \\
\text { nie. } \\
\text { Hebreërs } 13 \text {. Vermaning oor } \\
\text { praktiese aangeleenthede. }\end{array}$ \\
\hline an vertroosting. & \\
\hline
\end{tabular}




\subsection{Afleidings}

Uit hierdie oorsig van die wyer struktuur, gedagtestruktuur en 'n aantoning van die struktuur waarbinne verklaring en toepassing in die Hebreërpreek voorkom, kan die volgende afgelei word:

- Struktuur in verklarende prediking is noodsaaklik ter wille van kohesie en logiese progressie van gedagtes.

- Die patroon van uiteensetting, direk gevolg deur toepassing binne die Hebreërpreek, is nie alleen 'n ruggraat in die metodiek van preekmaak nie, maar bring ook balans in die preek. Vermaning in 'n preek sonder die fondament van die vermaning is moralisme en prediking alleenlik van die fondament van die vermaning, maar sonder 'n toepaslike appèl, kan die gemeente bring tot 'n toestand van 'n valse rus oor hulle geloofslewe.

Through the reiteration of central motifs - encouraging words, warnings and examples - the author (i.c. preacher) repeatedly hammers home the reward of a right decision on the part of the community and the punishment awaiting those who make a bad decision (Guthrie, 1994:139).

- Binne die behandeling van die belang van die preekstruktuur moet ook gewys word op preekoorgange in Hebreërs. Telkens in 'n eksplikasie volg oorgangsuitdrukkings om kohesie te bewerk tussen die uiteensetting en die vermaning. Die volgende geld as voorbeelde van oorgange: Hebreërs 2:1 "om hierdie rede" ( $\delta$ ı̀ то ӱто), Hebreërs 3:1 "daarom" ("2 $€ \nu$ ), Hebreërs 4:14 "dan" (o€v), Hebreërs 6:1 "daarom"

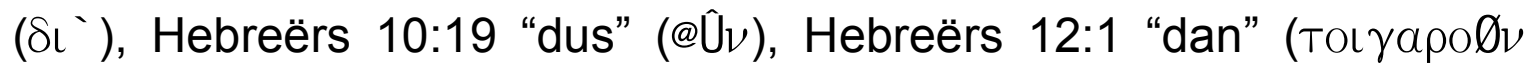
$\kappa a \neg \ldots)$.

Dié voorbeelde van logiese oorgange bind nie alleen die uiteensetting en die vermaning saam nie, maar illustreer ook dat uiteensetting en vermaning basies een is, soos twee kante van een muntstuk. Sowel uiteensetting as vermaning is deel van die één beweging van die Woord wat die werklikheid indring.

\section{Die element van preekinleiding}

Die inleiding van 'n preek funksioneer soos die voorportaal van 'n huis waardeur die gaste die huis binnekom. Die portaal is deel van die huis waar gaste die eerste indruk van die huis kry, maar die portaal is ook die deurgang om so gou moontlik by die res van die huis te kom. 
Die funksie van die inleiding is dus om die hoorder so gou moontlik by die behandeling van die tema as samevatting van die kerugma van die preekteks te bring, met ander woorde om die gemeentelid te bring by die Woord van God (vgl. Bae, 1991:88). In wese word in 'n goeie preekinleiding dus die hoofelemente van die hele preek in kern saamgevat soos wat byvoorbeeld Sondag 1 van die Heidelbergse Kategismus elemente bevat van al 52 Sondae in die Kategismus (Venter, 1991:50).

'n Verdere funksie van die preekinleiding is om die gemeente te oortuig dat hulle nie anders kan as om na die preek wat volg te luister nie (Vines, 1985:140) en om die toepaslikheid van die preektema te verstaan.

'n Nadere analise van die inleiding in Hebreërs 1:1-4 kan lig op bogenoemde stellings werp. In hierdie perikoop is eerstens sprake van een Spreker (God) in twee bedelings (vgl. Kistemaker, 1984:27).

\begin{tabular}{|l|l|}
\hline Ou bedeling & Nuwe bedeling \\
\hline Baie keer & Vir eens en vir altyd \\
Baie maniere & (Op 'n finale wyse) \\
Het God gepraat & Het God gepraat \\
$\begin{array}{l}\text { in die ou tyd } \\
\text { tot die vaders } \\
\text { deur die profete }\end{array}$ & $\begin{array}{l}\text { nou (in hierdie laaste dae) } \\
\text { tot ons } \\
\text { deur die Seun }\end{array}$ \\
\hline
\end{tabular}

Die gemeenskaplike faktor in hierdie vergelyking tussen die twee bedelings, is dat God gepraat het. Hoorbaar openbaar God Homself. Soos wat God finaal deur die Seun gepraat het in die nuwe bedeling, so het die Seun deur die apostels gepraat en die apostels het onder leiding van die Heilige Gees die Woord van God geskryf. "Het God gepraat" het dus direk betrekking op sy selfopenbaring wat op Skrif gestel is (Venter, 1986:11).

Die wyse waarop God praat, kom ook in hierdie gedeelte na vore. God het baie keer (letterlik in baie stukke) gepraat. Hy sê nie alles op een keer nie. In sy selfopenbaring was daar planmatigheid en voortgang na 'n bepaalde punt: van profete na Seun, van die verlede na nou en van die vaders na ons. Deur die eeue verbind God sy spreke aan 'n bepaalde situasie en rig dit op mense in die bepaalde situasie. 
God het gepraat toe en nou. Wie dus nou preek, moet God self aan die Woord laat kom in verklarende prediking - en dit op 'n planmatige wyse (Adam, 1996:10).

'n Volgende lyn wat ook in die inleiding van die Hebreërpreek na vore kom en dwarsdeur die preek loop, word in vers drie gestel "... nadat Hy die reiniging van ons sondes bewerk het ...." Die begrip reinig het direk betrekking op die Ou-Testamentiese hoëpriester wat homself eers moes reinig en dan ingaan in die allerheiligste om vir die sonde van die volk te offer. Christus, die Hoëpriester, hoef Homself nie te reinig nie - Hy reinig ons van ons sonde. Hierdie lyn verbind die inleiding van die Hebreërpreek met die sentrale inhoud van die Skrif en van elke preek: God het sy volk gereinig van hulle sonde.

Voorts loop die verdere uitdrukking in vers 3 “... het Hy gaan sit aan die regterhand van die Majesteit in die hoë hemel" ook regdeur die Hebreërpreek. Dit is die vertrekpunt van waaruit Christus, Oorwinnaar, beskryf word as "meer verhewe".

Guthrie (1994:27) beskryf hierdie "meer as" van Christus in die volgende struktuurpatroon:

- Christus meer as die profete (1:1-3)

- Christus meer as die engele (1:4-2:18)

- Christus meer as Moses (3:1-4:13)

- Christus meer as Aäron (4:14-10:18)

- Christus "die hoogste" as 'n nuwe en lewende weg (10:19-12:29)

Laastens word die aandag gevestig op die - homileties gesproke verrassende element in die inleiding. Die liggaam van die preek word later gevorm deur die verwysing na die werk van ons groot Hoëpriester, die ryke erfenis wat ons ontvang het, en die oproep tot ons om in geloof en hoop te volhard. Maar met die eerste oogopslag skyn dit nie asof dit presies is wat die prediker in die oog het met sy inleiding nie.

Tog blyk die prediker se aksie om met die inleiding direk by sy hoorders se situasie te begin en hulle sodoende te dwing om na die verdere verloop van die preek te luister. Hy sluit direk by hulle verlede aan vaders, profete, baie maniere. En dan, omskrywend gestel, wil die prediker sê: Nou sê ek iets waarna julle net móét luister, anders is julle armer. Nou praat God met julle, finaal in sy Seun. En die goeie nuus (evangelie) wil ek aan julle meedeel: Hy het julle gereinig. Hy is nou julle Koning. 


\section{Elemente van die liggaam van die preek}

Hierdie elemente kom in die Hebreërpreek na vore as explicatio en applicatio (vgl. die struktuurontleding). In meer resente homiletiese literatuur word die explicatio verdeel in die stappe van "investigation" en "interpretation" (Vines, 1985:68-94), gevolg deur die applicatio.

Wat opvallend is in die Hebreërpreek is - soos in punt 1 gestel - dat sowel explicatio as applicatio deurgaans in die verskillende onderdele deur die preek heen saam voorkom. Daar word met ander woorde nie 'n skeiding gemaak tussen die twee preekelemente van verklaring en toepassing nie, in die sin dat één toepassing heel op die end geplaas word, gevolg deur die slot van die preek nie. Dié vasstelling lei daartoe om as homiletiese reël neer te lê dat 'n preek verklarende toepassing en toepaslike verklaring aan die gemeente behoort te bied dwarsdeur die preek heen.

Dit bly insiggewend om die wyse waarop die Hebreërprediker toepas, nader te omlyn. Homileties gesproke, moet vanuit die proses van eksegese die telos (doel) van 'n bepaalde preekteks vasgestel word deur die vraag te stel waarom die Heilige Gees hierdie teks op hierdie plek in die Bybel laat inskryf het. Vanuit die telos van die preekteksperikoop word ook die doel van die prediker met die bepaalde preek geformuleer, byvoorbeeld om die gemeente te vermaan om ..., te vertroos in ..., nader in te lig oor ..., te wys op ...

'n Nadere analise van die enkele begrippe in die preektoepassings in Hebreërs dui ook die doel van die bepaalde deel van die Hebreërpreek aan:

- Na die uiteensetting van die preek in hoofstuk 1 , volg direk in hoofstuk 2:1 "Om hierdie rede moet ons ... vasgryp ( $\pi \rho O \sigma \chi \chi \in L \nu)$ aan wat ons gehoor het". Dus: 'n doel van die prediker was om die gemeente te laat vasgryp.

- 'n Volgende preekdoelwit kom in die toepassing in 3:1 na vore: “... moet julle noukeurig let op Jesus ...". In Hebreërs 3:12 kom die preekdoelwit in die volgende toepassing na vore: "Broers julle moet toesien dat daar nooit by een van julle 'n verkeerde gesindheid van ongeloof ontstaan nie".

- In Hebreërs 4:1 word die preek toegepas in: "oppas", "nie agterbly nie" en in vers 11 "beywer".

- In hoofstuk 5 en 6:1 word die doel van die preek bereik in die vermaning "julle is traag om te leer", en "laat ons nie stilstaan nie". 
- Besonder opvallend is dat die preekdoel in die latere hoofstukke (veral hoofstuk 12) oorgaan in die aansporing tot volharding. In hoofstuk 12:1 word die gemeente opgewek: Laat ons met volharding (fho $\mu \mathrm{ovZ}$ ) die wedloop loop wat voor ons lê. Dit is belangrik om daarop te let dat die fhro $\mu \nu \nu Z$ van vers 1 verbind word aan Christus se volharding ("die kruis verduur") in vers 3 (fhто $\mu \in \mu \in \nu \eta \kappa^{`}$ ' $\tau$ )!

Op grond van die uiteensetting hierbo kan dus gestel word

- dat die teksdoelwit by die tekstoepassing bring;

- homileties gesproke, moet daar kongruensie wees tussen die verklaring van die teks en die toepassing van die teks.

\section{Die element van die preekslot}

Wat die preekslot betref, stel homilete dat die volgende vereistes geld vir 'n preekslot: die slot moet die preek afsluit, nie nuwe materiaal bevat nie, kort, helder, toepaslik geformuleer word en positief wees (Bae, 1991: 163-172).

Die preekslot van Hebreërs word gevind in hoofstuk 13:20 en 21.

'n Nadere ontleding van hierdie verse toon verskillende toespelings op die inleiding en liggaam van die Hebreërpreek.

- In hoofstuk 1:1 staan God sentraal (God het gepraat)

- In hoofstuk 13:20 staan God weer sentraal as God wat vrede gee.

- In hoofstuk 1:3 word gestel dat Christus die reiniging van ons sondes bewerk het en toe (d.w.s. na sy opstanding en hemelvaart) aan God se regterhand gaan sit het.

- Hoofstuk 13:20 bied 'n toespeling op albei uitdrukkings in 1:3, naamlik "bloed van die ewige verbond" en "uit die dood teruggebring".

- In hoofstuk 4:14 word Jesus die "groot Hoëpriester" oor die huis van God genoem.

In die preekslot word Hy die "groot Herder" van sy kudde genoem.

Op grond van bostaande ooreenkomste is dit redelik om af te lei dat die Hebreërpreek in sy samestelling die patroon van 'n ringkomposisie vertoon. Waarmee die prediker begin het, daarmee eindig hy nou weer kerugmaties. Voorafgegaan deur 'n wyer toepassing (hoofstuk 13:1-20) in sy preek, trek die prediker die hooflyne van die preek saam in die slot van sy preek. 


\section{Die element van die spiritualiteit van die bedienaar}

Vroeër is homiletiese navorsing sterk gerig op die preek as sodanig. 'n Latere ontwikkeling was dat nader gefokus is op die prediker en dan in besonder op sy eie persoonlike geloofslewe, op sy spiritualiteit wat omskryf kan word as die lewe van die prediker coram Deo, sy lewe voor, onder die oë van God (Velema, 1992:28).

Verskeie nuanses in hierdie spiritualiteit is reeds nader ondersoek, onder andere die fundering van spiritualiteit (Venter, 1999:6-7; vgl. Drane, 1997:332-340), die werking van die spiritualiteit in die lewe van die prediker (Kim \& Venter, 1998:175-176) en die praktyk van die lewe voor God (Paterson, 1997:21-24). As besondere element vir die beoefening van die spiritualiteit van die prediker word gewys op sy omgang met God deur die Skrif, sy bepeinsing van die Skrif en sy gebedslewe.

'n Dimensie hiervan kom na vore in Hebreërs 10:21 en 22. "En terwyl ons Hom ook as groot Priester oor die huis van God het, laat ons tot God nader met 'n opregte hart en met volle geloofsekerheid. Ons harte is immers gereinig van ' $n$ skuldige gewete en ons liggame is gewas met skoon water".

Die volgende aspekte kom in hierdie verse na vore:

- Die fundering vir ons omgang met God lê enersyds in die feit dat ons 'n groot Priester het. As Priester het Hy Homself gegee as offer (vgl. Hebreërs 10:19 en 20). Andersyds is hier sprake daarvan dat ons harte gereinig is ('n motief wat reeds van Hebreërs 1 af deurloop). Ons gewete is skoon gewas. Ons mag as gereinigdes tot God nader.

- Die uitdrukking "tot God nader" verdien nadere ondersoek. Die begrip $\pi \rho \circ \sigma \in \rho \chi \omega \mu \in \theta \alpha$ is kohortatief en staan in die medium dus: ons het 'n groot Priester, ons is gereinig, laat ons daarom vanself nader gaan, ingaan na God toe. Die Griekse uitdrukking vir nadergaan, is dieselfde as dié wat in die Septuagint gebruik word vir die nadergaan of ingaan van die Ou-Testamentiese hoëpriester, eenmaal per jaar om te bid en te offer vir die volk Israel. Die doel van die ingaan tot God was onmiskenbaar dié van gebed. Die bewyse hiervan lê in Hebreërs 4:16 waar dieselfde begrip (gaan) soos volg gebruik word: "Kom ons gaan dan met vrymoedigheid na die genadetroon, sodat ons barmhartigheid en genade ontvang en so op die regte tyd gered kan word". Die gebed is gerig op die ontvang van genade.

- 'n Verdere nuanse in die element van die spiritualiteit van die bedienaar kom na vore in: Laat ons nader met ' $n$ opregte hart. Ons is meervoud en ' $n$ is enkelvoud. Dus: Ons kan almal tot God nader, 
maar met ons hart staan ons elkeen individueel en afsonderlik voor God! Juis daarom word die vereiste gestel dat ons met 'n opregte (waaragtige, onverdeelde) hart moet gaan. In ons gaan tot God is egter nie net sprake van 'n onverdeelde hart nie, maar ook van volle geloofsekerheid, dié sekerheid wat lei tot 'n heel, onverdeelde lewe in die teenwoordigheid van God.

Die persoonlike geloofslewe van die bedienaar en sy gesindheid teenoor God kom sterk na vore, hier in besonder in die een voedingsbron van sy spiritualiteit, naamlik sy gebedslewe in die binnekamer.

\section{Die element van toerusting tot groei deur die prediking}

Die element van toerusting deur prediking kom wel in Hebreërs voor. In Hebreërs 3 kom toerusting as 'n aspek van bouwerk na vore. "God is die een wat alles gebou het" (3:4) en: "Ons is die huis van God". In die laaste hoofstuk van Hebreërs (13:21) word in die prediker se gebed vir die Hebreërs gebid: "Mag dié God julle toerus met alles wat goed is, sodat julle sy wil kan doen". Toerus word hier dus verbind aan die doen van die wil van God.

Die toerusting deur die Woord kom egter besonder prominent na vore in Hebreërs 6:1(a). Omskrywend kan wat hier staan, soos volg weergegee word. Ons (die prediker), wil graag die moeiliker dinge in die Skrif aan julle verduidelik, maar julle is traag (stadig, lui, gevoelloos) om te verstaan. Die groot probleem is dat julle met melk gevoed moet word. Julle is so lank al gelowiges dat julle al ander moes leer. Intussen kan ons julle nie voed met vaste kos nie. Julle het nie gegroei nie. Julle kan (soos 'n suigeling) nie goed en kwaad onderskei nie.

Die feit dat die gemeente juis deur die Woord gevoed word, word helder gestel in Hebreërs 6:1 in die uitdrukking “... die eerste dinge wat aangaande Christus verkondig is ..." en "... verder gaan na die volle inhoud van die boodskap".

\section{Die element van die prediker se verhouding tot die gemeente}

Homilete beklemtoon steeds meer en meer dat die verhouding waarin 'n prediker tot die gemeente staan, 'n besliste invloed op die prediking het (Vines, 1985:32; Willhite, 1992:355; Pieterse, 2001:28).

Die kernvraag hier is of daar op basisteoretiese vlak in die Hebreërpreek sprake is van die verhouding tussen prediker en gemeente. 
Hierdie saak kom ter sprake in Hebreërs 6:9-12. Die Hebreërprediker gebruik min keer 'n aanspreekvorm vir die gemeente in sy preek. Hier gebruik hy die uitdrukking "geliefdes". Hierdie aanspreekvorm moet in konteks gesien word. Vanaf Hebreërs 6:4-8 vermaan hy die gemeente só skerp, "als bliksemen" (Calvyn, 1972:85). Met die uitdrukking "geliefdes" gee die prediker nou te kenne dat hy hulle steeds liefhet, omdat sowel prediker as gemeente deel in dieselfde reinigingswerk van die groot Hoëpriester. Juis omdat hy in 'n verhouding van liefde tot die gemeente staan, kan hy skerp vermaan, maar kan hy ook opregte waardering betuig "al praat ons in hierdie trant is ons oor julle oortuig van beter: dat julle gered sal word" (vers 9). Die waardering word gevolg deur “... Hy (God) sal julle werk nie vergeet nie en ook nie die liefde wat julle vir sy naam betoon het deurdat julle julle medegelowiges gedien het en nog dien" (vers 10). Die kern van die prediker se verhouding met sy gemeente hier is: julle is geliefdes wat reeds julle liefde aan julle naaste bewys het.

\section{Samevatting van basisteoretiese elemente met die oog op verklarende prediking}

- 'n Preek moet sodanig gestruktureer word dat dit 'n eenheid vorm wat kohesie en logiese progressie in die preek bevorder, in besonder deur ook gebruik te maak van vloeiende oorgange tussen paragrawe.

- Toepaslike verklaring en verklarende toepassing behoort deurgaans en nie afsonderlik nie - in 'n preek voor te kom omdat verklaring en toepassing basies dele is van dieselfde beweging van die Woord wat die werklikheid indring.

- Die preekinleiding moet die kern bevat van die elemente wat in die preek aan die orde gaan kom.

- Preekdoelwit(te) moet vanuit die telos van die preekteks geformuleer word en in die toepassing in kongruensie met die uitleg geformuleer word.

- Ideaalgesproke moet die preekslot aansluit by die preekinleiding en sodoende saam 'n ringkomposisie vorm.

- Die gehalte van die persoonlike geloofslewe en geloofsomgang van die bedienaar met God bepaal in 'n groot mate die gehalte van sy prediking.

- Toerusting van die gemeente in prediking geskied deur in die prediking te fokus op groei-agterstande. 
- Die prediker wat sy gemeente liefhet en dit so aan hulle bewys, kan vanuit die liefde die gemeente ook skerp vermaan. Liefde en vermaning sluit mekaar in.

\section{Bibliografie}

ADAM, P. 1996. Speaking God's Words. Illinois : Inter-Varsity.

ALLEN, D.L. 2000. A tale of two roads: Homiletics and biblical authority. Journal of the Evangelical Theological Society, 43(3):489-516.

BAE, G.H. 1991. A homiletical research on structure in a Reformed sermon. Potchefstroom : PU vir CHO. (Th.D.-proefskrif.)

BUGG, C. 1993. Back to the Bible: toward a new description of expository preaching. Review and Expositor, 90:413-421.

CALVYN, J. 1972. Uitlegging op de zendbrief aan de Hebreën. Goudriaan : De Groot. (Bewerk deur A.M. Donner.)

CHAPELL, B. 1995. Components of expository preaching. Preaching, X(6):4-14.

COETZEE, J.C. 1986. Gedagtestruktuur van Hebreërs. Potchefstroom : Fakulteit Teologie.

DENNISSON, G.K. 1996. Some thoughts on preaching. Kerux, (11):3-9.

DEUEL, D.C. 1991. An Old Testament pattern for expository preaching. The Masters Seminary Journal, 2(2):125-133.

DRANE, J.W. 1997. Christian responses to the New Age spirituality. Foundations, 40:10-17.

GROSHEIDE, F.W. 1955. De Brief aan de Hebreën en de Brief van Jakobus. Kampen : Kok.

GUTHRIE, G.H. 1994. The structure of Hebrews. Leiden : Brill.

HEWITT, T. 1975. Hebrews. Londen : Inter-Varsity.

HURST, L.D. 1990. The epistle to the Hebrews. Its background and thought. Cambridge : University Press.

KIM, H.K. \& VENTER, C.J.H. 1998. Preacher and spirituality: perspectives from the Pastoral Epistles. In die Skriflig, 32(2):161-180.

KISTEMAKER, S.J. 1984. New Testament Commentary. Exposition of the Epistle to the Hebrews. Grand Rapids : Baker.

LAWSON, S.J. 2001. The priority of biblical preaching: an expository study of Acts 2:42-47. Bibliotheca Sacra, 158(630):198-217.

LINDARS, B.L. 1991. The theology of the letter to the Hebrews. Cambridge : University Press.

LONG, T.G. 1989. The witness of preaching. Westminster : John Knox.

OPPERMAN, W.C. 1995. Die motief van vreemdelingskap en vaderland in Hebreërs - 'n eksegetiese studie met toespitsing op Hebreërs 11:8-22. Potchefstroom : PU vir CHO. (Th.D.-proefskrif.)

PATERSON, A. 1997. A spirituality of Word and Spirit for a post-modern world. Foundations, 39:21-24.

PIETERSE, H.J.C. 2001. Prediking in 'n konteks van armoede. Pretoria : Unisa.

ROBINSON, H. 1997. The heresy of application. Leadership, 21-27, Fall.

STITZINGER, J.F. 1992. The history of expository preaching. The Master's Seminary Journal, 3(1):5-32.

VELEMA, W.H. 1992. Geloof en gevoel. Leiden : Groen \& Zoon.

VENTER, C.J.H. 1986. Gemeente-opbou in die lig van Hebreërs. Potchefstroom : PU vir $\mathrm{CHO}$. 
VENTER, C.J.H. 1991. "Jou enigste troos": pastorale perspektiewe en motiewe uit die Heidelbergse Kategismus. In die Skriflig, 25(1):47-69.

VENTER, C.J.H. 1999. Die spiritualiteit van die bedienaar met verwysing na sy toerustingstaak. In die Skriflig, 33(2):187-202.

VENTER, C.J.H. 2001. Verklarende (expository) preaching - 'n herevaluering. Aanvaar vir publikasie in In die Skriflig, 35.

VINES, J. 1985. A practical guide to sermon preparation. Chicago : Moody.

WILLHITE, K. 1992. Audience relevance in expository preaching. Bibliotheca Sacra, 149(594):355-369.

\section{Kernwoorde:}

preekstruktuur: inleiding, liggaam, slot, spiritualiteit.

toerusting van die gemeente

verklarende prediking

\section{Keywords:}

equipping the congregation

expository preaching

sermon structure: introduction, conclusion, body, spirituality. 